\title{
Inflammatory myofibroblastic tumor:
}

\section{an unusual submucosal lesion of the stomach}
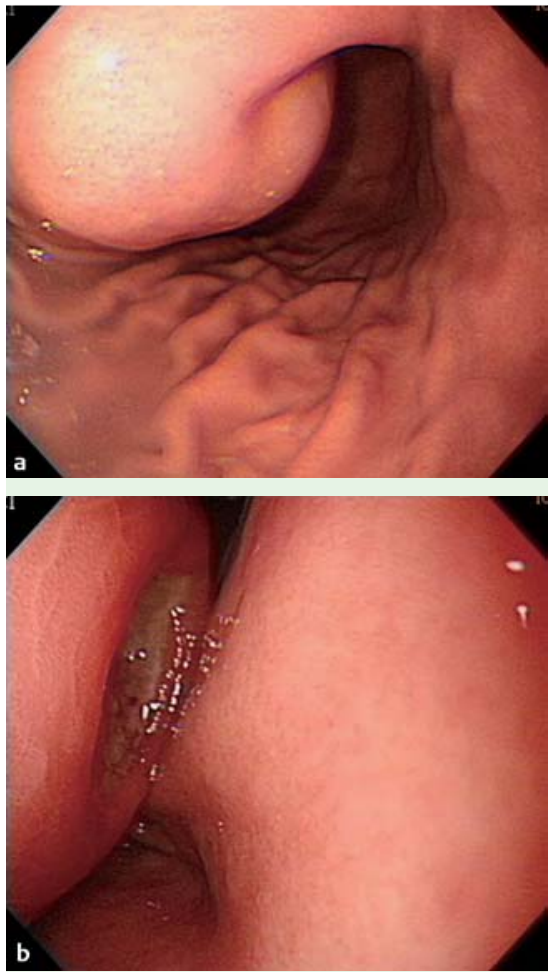

Fig. 1 a, b Upper endoscopy showing a broadbased, protruding mass, approximately $5.5 \mathrm{~cm}$ in size, in the anterior wall of lower gastric body. The tumor is accompanied by bridging folds and two deep ulcerations on the surface.

Inflammatory myofibroblastic tumor (IMT) is a mesenchymal tumor that occurs preferentially in children and young adults. IMTs were considered arise as a result of a reactive inflammatory or post surgery process [1]. However, they are thought to have low-grade malignant potential, based on the recent molecular finding of rearrangement at chromosome band $2 \mathrm{p} 23$, the site of the anaplastic lymphoma kinase $(A L K)$ gene in the tyrosine kinase locus [2]. They are most commonly found in the lung but may arise in extrapulmonary sites [3].

A 42-year-old woman presented with intermittent dull epigastric pain since 1 month and tarry stool passage since 1 week. The laboratory findings were unremarkable except for a normocytic anemia (hemoglobin $7.7 \mathrm{~g} / \mathrm{dL}$ ). Upper endoscopy

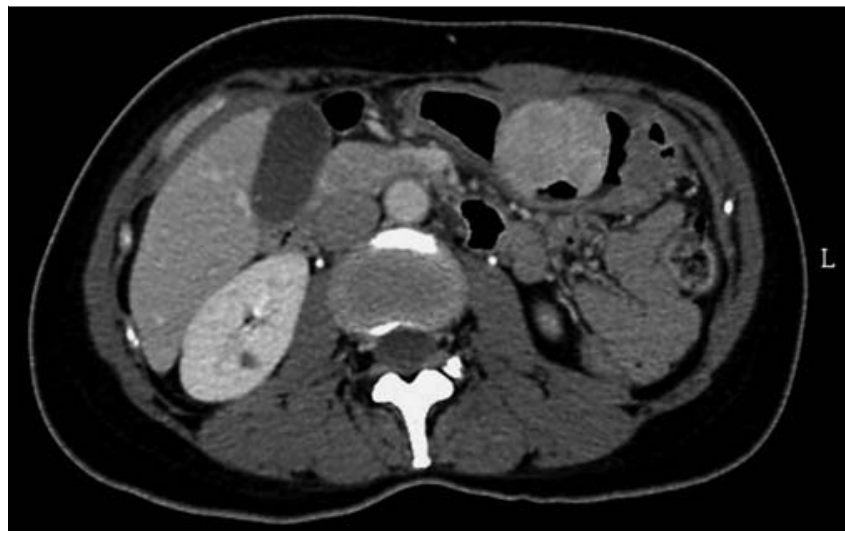

Fig. 2 Abdominal computed tomography (CT) scan demonstrating a strongly enhancing mass, approximately $5.5 \mathrm{~cm}$ in size, with surface ulceration, arising from the submucosal layer of the anterior wall of the lower gastric body.

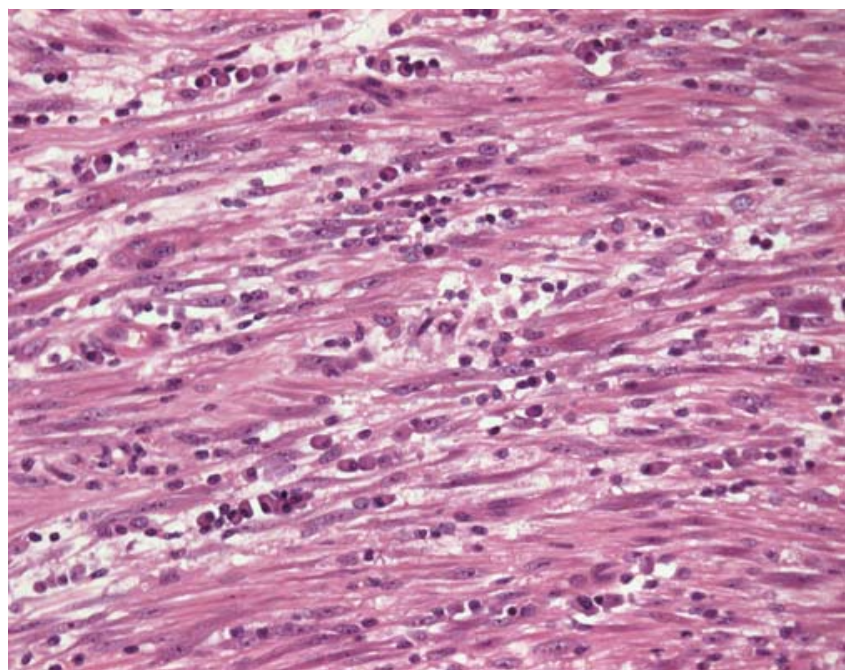

Fig. 3 Microscopic section showing the tumor composed of spindle cells with massive, predominantly inflammatory, infiltration of plasma cells (hematoxylin and eosin, magnification $\times 40$ ).

revealed a broad-based, protruding mass of approximately $5.5 \mathrm{~cm}$, located in the anterior wall of lower gastric body. The tumor was accompanied by bridging folds and two deep ulcerations on its surface ( Fig. 1). Abdominal computed tomography (CT) demonstrated a strongly enhancing mass with surface ulceration, arising from the submucosal layer ( $\bullet$ Fig. 2), which was in keeping with a submucosal lesion such as a gastrointestinal stromal tumor (GIST). The patient underwent local tumor excision. Microscopically, the tumor was composed of spindle cells with massive infiltration of plasma cells ( Fig. 3). IMT was diagnosed by immunohistochemistry (IHC), which showed positive staining for desmin and smooth muscle actin and was negative for GIST markers including CD117, DOG1, CD34, and
S100. Kit-negative GIST was further excluded as there no mutations in the c-KIT and PDGFRA genes.

Gastric IMT is very rare and may be confused with other submucosal lesions, especially GIST, and IHC studies are the only conclusive diagnostic modality [4]. When investigating a gastric submucosal lesion, IMT should be taken into consideration particularly if the patient is young or the pathology shows massive plasma cell infiltration admixed with spindle cells.

Endoscopy_UCTN_Code_CCL_1AB_2AD_3AB

Competing interests: None 


\section{Y. K. Lee, H. Y. Wang, L. R. Shyung, \\ C. W. Chang, M. J. Chen}

Division of Gastroenterology, Department of Internal Medicine, Mackay Memorial

Hospital and Mackay Medicine, Nursing and Management College, Taipei, Taiwan

\section{References}

1 Leon CJ, Castillo J, Mebold J et al. Inflammatory myofibroblastic tumor of the stomach: an unusual complication after gastrectomy. Gastrointest Endosc 2006; 63: 347-349

2 Sukov WR, Cheville JC, Carlson AW et al. Utility of ALK-1 protein expression and ALK rearrangements in distinguishing inflammatory myofibroblastic tumor from malignant spindle cell lesions of the urinary bladder. Mod Pathol 2007; 20: 592-603

3 Coffin CM, Watterson J, Priest JR et al. Extrapulmonary inflammatory myofibroblastic tumor (inflammatory pseudotumor). A clinicopathologic and immunohistochemical study of 84 cases. Am J Surg Pathol 1995; 19: 859-872

4 Greenson JK. Gastrointestinal stromal tumors and other mesenchymal lesions of the gut. Mod Pathol 2003; 16: 366 - 375

\section{Bibliography}

DOI $10.1055 / \mathrm{s}-0030-1256257$

Endoscopy 2011; 43: E151 -E152

(c) Georg Thieme Verlag KG Stuttgart - New York . ISSN 0013-726X

\section{Corresponding author}

\section{Dr. M. J. Chen}

Division of Gastroenterology

Department of Internal Medicine

Mackay Memorial Hospital

No.92, Sec. 2 Chung-Shan North Road

Taipei

Taiwan

Fax: +886-2-25433642

mingjen.ch@msa.hinet.net 